\title{
The Scavenger Effect - does it work?
}

\author{
W. Bohmeyer* ${ }^{\text {a,d }}$, F.L. Tabares ${ }^{\mathrm{b}}$, M. Baudach ${ }^{\mathrm{a}, \mathrm{g}}$, A. Cwiklinski ${ }^{\mathrm{e}}$, A. Markin $^{\mathrm{c}}$, T. Schwarz- \\ Selinger $^{\mathrm{g}}$,J.A. Ferreira ${ }^{\mathrm{b}}$, G. Fussmann ${ }^{\mathrm{a}, \mathrm{d}}$, and A. Loarte ${ }^{\mathrm{f}}$ \\ ${ }^{a}$ AG Plasmaphysik der Humboldt Universität, Newtonstr. 15, D-12489 Berlin, Germany \\ ${ }^{b}$ Euratom Ciemat Association, 28040 Madrid , Spain \\ ${ }^{c}$ Institute of Physical Chemistry, Russian Academy of Sciences, Moscow, Russia \\ ${ }^{d}$ Max-Planck-Institut für Plasmaphysik, EURATOM Ass. Wendelsteinstr. 1, 17491 Greifswald, \\ ${ }^{e}$ Fachbereich für Physik, FU Berlin, Arnimallee 14, D-14159 Berlin \\ ${ }^{f}$ EFDA closed support unit,D-85748 Garching,Boltzmannstr.2 Germany \\ ${ }^{g}$ Max-Planck-Institut für Plasmaphysik, EURATOM Ass.Boltzmannstr.2 D-85748 Garching
}

\begin{abstract}
The influence of nitrogen injection on the formation of a-C:H films in areas far away from the plasma as well as close to the plasma boundary was studied in the PSI-2 device for collector temperatures between 310 and $350 \mathrm{~K}$. The balance between deposition and erosion determines the net growth rate. Small amounts of nitrogen $\left(\Phi\left(\mathrm{N}_{2}\right) \approx \Phi\left(\mathrm{CH}_{4}\right) \approx 2 \% \Phi\left(\mathrm{H}_{2}\right)\right)$ strongly reduce the net growth rate in $\mathrm{H}_{2} / \mathrm{CH}_{4}$ mixtures. While $\mathrm{N}_{2}$ injection does not influence erosion far away from the plasma it increases erosion close to the plasma boundary. The experiments show clear evidence for a scavenger effect due to the injected nitrogen. The conversion from $\mathrm{N}_{2}$ to active species takes place in the hot plasma region.

JNM Keywords: C0100 Carbon, S1300 Erosion, F0800 Fusion Reactor Materials

PSI-18 Keywords: Amorphous films, Carbon films, Coating, Graphite, Erosion

PACS: $81.15,52.55$ Fusion
\end{abstract}

Presenting and corresponding author: werner.bohmeyer@ipp.mpg.de 


\section{Introduction}

The positive properties of carbon and CFC materials as wall material for high heat fluxes are well known. On the other hand, all carbon materials provide a source for a-C:H films (or flakes) in the plasma near region in which tritium can be deposited. Two ways to solve this problem are obvious:

-All CFC components will be replaced by other materials thereby accepting other disadvantages.

-The area of CFC, and as a consequence the amount of eroded material, should be reduced to a minimum. As long as carbon will be used as first wall material, cleaning techniques to remove the tritium need to be developed. This procedure must be compatible with the normal operation of the device.

A possible procedure for avoiding a-C:H film formation is the application of scavenger atoms or molecules. The idea is that gas phase reactions between reactive growth precursors and scavenger species reduce or inhibit film growth. Pioneering work concerning nitrogen as scavenger gas was done by Tabares $[1,2]$.

The interaction of nitrogen with carbon containing plasmas is a very complex process. In the literature different diagnostics were applied to study the interaction between nitrogen and hydrogen containing mixtures. In fact, one can find a lot of information for totally different experimental conditions: catalyser based HCN production at atmospheric pressure [3] , production of synthetic materials and gas phase reactions in microwave plasmas $[4,5]$, low temperature plasma studies $[6,7,12,13]$ as well as experiments in fusion experiments [8]. The spectrum of intermediate species and final products covers nearly all possibilities for $\mathrm{C}_{\mathrm{x}} \mathrm{H}_{\mathrm{y}} \mathrm{N}_{\mathrm{z}}$ (for $\mathrm{x}=1,2, . . \mathrm{y}=1 \ldots 6, \mathrm{z}=1,2$ ). In reference [3] threshold quadrupole mass spectrometry was applied to solve the problem of ambivalent mass spectra, and some of the information can be successfully applied to our experiments. In [9] it is shown that e.g. gas phase reaction rates with $\mathrm{NH}_{3}$ for high sticking species such as $\mathrm{C}_{2} \mathrm{H}$ are high. New methods to identify the 
chemical processes are the application of a cryo-trap at the exhaust for collecting small amounts of reaction products by condensation $(77 \mathrm{~K})$ and to analyse these species later during heating up of the trap [1,2]. It is obvious that the sensitivity of mass spectrometry can be increased by this method, but possible reactions between the condensed species are still an open question.

Another powerful method to evaluate the complex mass spectra and their cracking pattern is Bayesian data analysis $[11,12]$. It can even handle reactive species, but additional information is often needed when such complex spectra like in the case of $\mathrm{CH}_{4} / \mathrm{N}_{2}$ mixtures are analysed.

In the present work we focus upon the influence of injected nitrogen on the film growth rate in regions far away from the plasma and plasma neighbouring regions. In all these experiments it was ensured that ionized species cannot reach the collector.

\section{Experimental setup}

The experiments were performed in the PSI-2 plasma generator, a stationary high current arc discharge. The arrangement of the experiments is depicted in Fig. 1. The source region of the plasma is the discharge between anode and cathode. The working gas (here mainly $\mathrm{H}_{2}$, but also He and Ar) is injected through the cathode. Typical flow rates are in the range between 50 and $300 \mathrm{sccm}$. To avoid uncontrolled losses of injected $\mathrm{C}_{\mathrm{x}} \mathrm{H}_{\mathrm{y}}$ on cold walls an additional floating inner stainless steel tube, surrounding the plasma column, was inserted. The plasma was terminated by a floating tungsten plate, located near the end of this tube.

The tube is heated by the plasma and its temperature is measured by two thermocouples. After about 30 min the temperature reaches a constant value of $470 \mathrm{~K}$. A small amount of hydrocarbons or /and nitrogen (1-2 sccm) is injected into the tube. For such conditions the whole inner surface of the tube is erosion dominated. After such experiments no deposits are found on the tube. Consequently, we study the behaviour of re-eroded hydrocarbons in the 
experiments described below. About $50 \%$ of the injected species flow along the tube into a plasma free pump duct (estimation using both QMS). The residual $50 \%$ is found in the main chamber. A long tube (pump duct) of about $1.2 \mathrm{~m}$ in length is mounted behind the neutralizer plate at an angle of 90 degrees to the main axis. At the end of this duct a turbomolecular pump is installed. This region is always free of plasma. The deposition / erosion processes onto a movable temperature controlled collector are studied by means of white light reflectometry ( AvaSpec-102 and AvaSoft-Thinfilm, Mikropack).

In a second arrangement the deposition of injected $\mathrm{C}_{\mathrm{x}} \mathrm{H}_{\mathrm{y}}$, and /or the erosion near to the plasma - without the inner tube - were studied using the same technique. This time the temperature controlled collector is in the main chamber and hydrocarbons and nitrogen are injected opposite to it (see reference [15]). In both cases the neutral species are analysed by two quadrupole mass spectrometers (QMS), one connected to the main chamber, the other to the pump duct. These two arrangements allow studying the influence of nitrogen and nitrogen containing molecules on film formation by neutral species in the plasma vicinity and far away from it. The pressure at the cross point between generator and pump duct was measured using a Baratron. The experiments shown were performed at pressures of 0.1 and $1 \mathrm{~Pa}$.

\section{Experimental results and discussion}

In Fig. 2 the change of the film thickness on a collector $(\mathrm{T}=330 \mathrm{~K})$ in the duct is shown when injecting methane and /or nitrogen into the hot stainless steel tube. In clean hydrogen discharge an erosion rate (by atomic hydrogen) of about $-0.044 \mathrm{~nm} / \mathrm{min}$ is detected. Important to note, that addition of nitrogen does not influence the erosion rate (no surface reaction). This is in accordance with previous studies, where no influence was found, when particle energies are low [6]. However, if methane is present, nitrogen addition has a strong influence. If only methane $(2 \mathrm{sccm})$ is added, erosion turns over to net deposition with a growth rate of $\approx+0.031$ $\mathrm{nm} / \mathrm{min}$. Adding nitrogen totally balances the deposition and again erosion with 

$-0.043 \mathrm{~nm} / \mathrm{min}$ is found, the same value as in case of pure hydrogen plasma. The addition of nitrogen can thus be understood in the way that it converts all active hydrocarbons to nonsticking species, a mechanism denoted as "scavenger effect".

It is evident that the erosion rate depends strongly on the collector temperature. This temperature influence on the net rates is shown in Fig.3, where fluxes of methane and nitrogen are switched on and off for three temperatures. Assuming that the net rates can be described by a superposition of the individual processes - namely deposition by reactive hydrocarbons, erosion by atomic hydrogen and conversion of reactive hydrocarbons by nitrogen species, the carbon fluxes onto the collector as well as the amount of radicals "removed" by nitrogen can be estimated from the measured rates. As can be seen in Fig. 3 at $\mathrm{T}=310 \mathrm{~K}$ the carbon sticking rate amounts to $0.96+|-0.62|=1.58 * 10^{-3} \mathrm{~nm} / \mathrm{s}$ while at $\mathrm{T}=330 \mathrm{~K}$ we find $0.35+|-1.21|=1.56^{*} 10^{-3} \mathrm{~nm} / \mathrm{s}$. Similarly, the amount of hydrocarbons transformed by nitrogen to non sticking species is calculated from the transitions occurring at $\mathrm{t}=12000 \mathrm{~s}$ and $\mathrm{t}=22000 \mathrm{~s}$. At $\mathrm{T}=310 \mathrm{~K}$ the effect is $0.96-0.08=0.88 * 10^{-3} \mathrm{~nm} / \mathrm{s}$ whereas for $\mathrm{T}=330 \mathrm{~K}$ the rate is $0.35+|-0.66|=1.01 * 10^{-3} \mathrm{~nm} / \mathrm{s}$. Differences in the rates for the same conditions ( e.g. 1.62 and $0.91 \mathrm{~nm} / \mathrm{s} * 10^{-3}$ at $310 \mathrm{~K}$ )can be explained by an increase of the time constants for many masses, when nitrogen is included. It is seen that the carbon sticking rate and the nitrogen effect are nearly equal at 310 and $330 \mathrm{~K}$. Again, this is a further indication that the interaction of nitrogen with hydrocarbon radicals is rather a volume than a surface reaction.

For comparison, similar experiments were made where nitrogen was replaced by neon injection. The results are summarized in Fig. 4. Independent of the collector temperature neon does not influence film formation. Furthermore, the temperature dependence of erosion by atomic hydrogen is clearly maintained under such circumstances.

For studying a possible influence of injected nitrogen close to the divertor plates we used a collector near to the plasma. The results are shown in Fig. 5. In this case nitrogen injection 
reduces not only the deposition during methane injection (phase V) but increases the erosion in comparison to a clean plasma, too. Such a synergistic effect was observed previously for energetic particles $(>10 \mathrm{eV})[6]$. From this we conclude, that close to the plasma boundary energetic neutrals that hit the collector do influence the interaction. All QMS measurements show that the chemical reactions behind these processes are connected first of all with reactions between hydrocarbons, nitrogen and hydrogen $\left(\mathrm{NH}_{\mathrm{x}}, \mathrm{HCN}\right)$. It is obviously chemical sputtering that causes the erosion, as in clean Ar or He discharges the influence of injected nitrogen is reduced to a minimum if hydrogen is practically not available $[16,17]$. An evaluation of the on-going reactions can be done by applying the Bayesian data analysis; this is a subject of actual work [14].

\section{Summary}

The scavenger effect, the influence of nitrogen on the deposition of a: $\mathrm{CH}$ layers by conversion of highly sticking hydrocarbons to inert ones, has been demonstrated.

A similar influence was not found in case of argon or neon injection. The reactions are not caused by nitrogen proper but are rather related to hydrogen and nitrogen carrying species as a consequence of plasma chemical reactions. Despite the encouraging results found in this study, the beneficial use of $\mathrm{N}_{2}$ injection into fusion devices is not guaranteed yet, unless the enhanced erosion of the divertor plates by nitrogen can be shown to be tolerable. 
References:

[1] Tabarés, F.L.,Tafalla, D., Tanarro, I., Herrero,V., Islyaikin, A., Maffiotte, C. Plasma Phys. Contr. Fusion 2002, 44, L37

[2] J. A. Ferraira and F.L. Tabarés J,Vac.Sci.Technol. A25 (2007) 246-251

[3] R. Horn, G. Mestl, M. Thiede, F. C. Jentoft, P. M. Schmidt, M. Bewersdorf, R. Weber and R. Schlögl Phys. Chem. Chem. Phys. 2004, 6, 4514-21

[4] S.M. Leeds, P. W. May, M. N. R. Ashfold, K. N. Rosser Diamond and Related Materials 8 (1999) 226-230

[5] P. W. May, P. R. Burridge, C. A. R. Rego, R. S. Tsang, N. R. Ashfold, K. N. Rosser, R.E. Tanner, D. Cherns, R. Vincent Diamond and Related Materials 5(1996) 354-358

[6] T. Schwarz-Selinger, C. Hopf, C. Sun, W. Jacob Journal of Nuclear Materials 363-365 (2007) $174-178$

[7] Tanarro I. Herrero V.J. Islyaikin A.M. Mendez, I. Tabares, F.L. Tafalla, D. Ion chemistry in cold plasmas of $\mathrm{H}_{2}$ with $\mathrm{CH}_{4}$ and $\mathrm{N}_{2}$. Journal of Physical Chemistry A. 111(37):90039012, 2007 Sep 20.

[8]: F. L. Tabarés, V. Rohde, the ASDEX Upgrade Team, Plasma processing techniques for tritium inventory control in fusion devices, Plasma Phys. Contr. Fusion 46 (2004) B381.

[9] X.Zhang, Y. Ding, Z.Li, X. Huang, C. Sun J. Phys. Chem. A 104 (2000) 8375-8381

[10] B. Nizamov, St. R. Leone J. Phys. Chem. A 108 (2004) 3766-3771

[11] T. Schwarz-Selinger, R. Preuss,, V. Dose and W. von den Linden, J. of Mass Spectrometry 36 (2001) 866-874 
[12] H.D.Kang, R.Preuss, T. Schwarz-Selinger and V. Dose J. of Mass Spectrometry, 37

(2002) 748-754

[13] G. Fussmann et.al. Studies of Hydrocarbon Formation and Redeposition in ITER-

Relevant Divertor Chamber Conditions: EFDA Report TW4 -TPP-TRIDEP, Berlin 2006

[14] A. Cwiklinski, M.Baudach, to be published

[15] A. Cwiklinski Wechselwirkung zwischen Stickstoff und Kohlenwasserstoffen, Diploma thesis, TU Berlin 2008

[16]_W. Jacob, C. Hopf, M. Schlüter: „Chemical Sputtering of carbon by nitrogen ions“, Appl. Phys. Lett. 86 (2007) 204103

[17] M. Schlüter, C. Hopf, W. Jacob: „Chemical Sputtering of carbon by nitrogen“ accepted for publication in NJP (2008)

This work has been carried out within the research programme of the European Task Force on Plasma Wall Interaction and was partially supported by TW4-TPP-TRIDEP. 


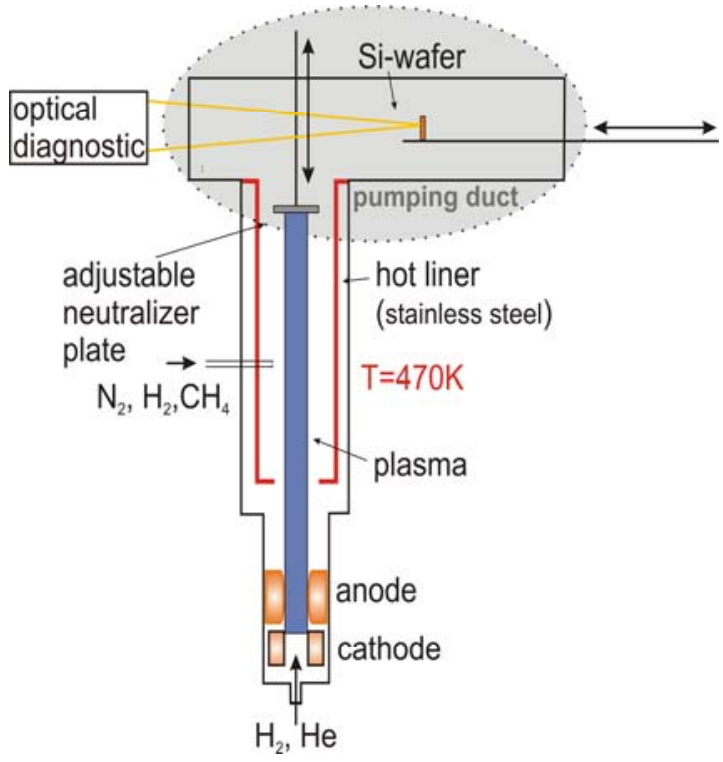

Fig.1:

Setup of the PSI-2 with hot liner surrounding the plasma for studying deposition and erosion far away from the plasma in the pump duct. 


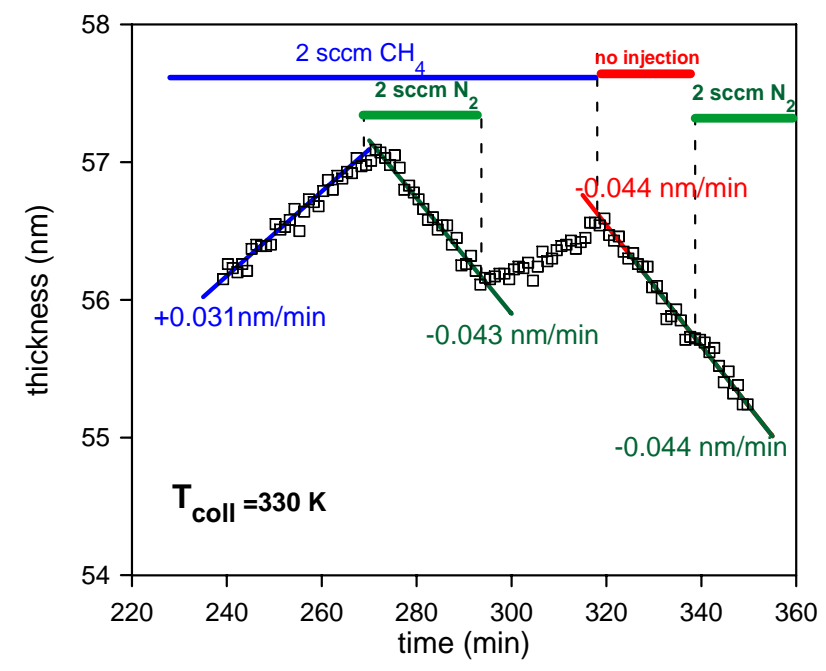

Fig. 2:

Film thickness in the pump duct vs. time for pure $\mathrm{H}_{2}$ plasma and injection of $\mathrm{CH}_{4}$ and / or $\mathrm{N}_{2}$.

Distance to the end of the hot wall $500 \mathrm{~mm}$, collector temperature $330 \mathrm{~K}$. Pressure $1 \mathrm{~Pa}$. 


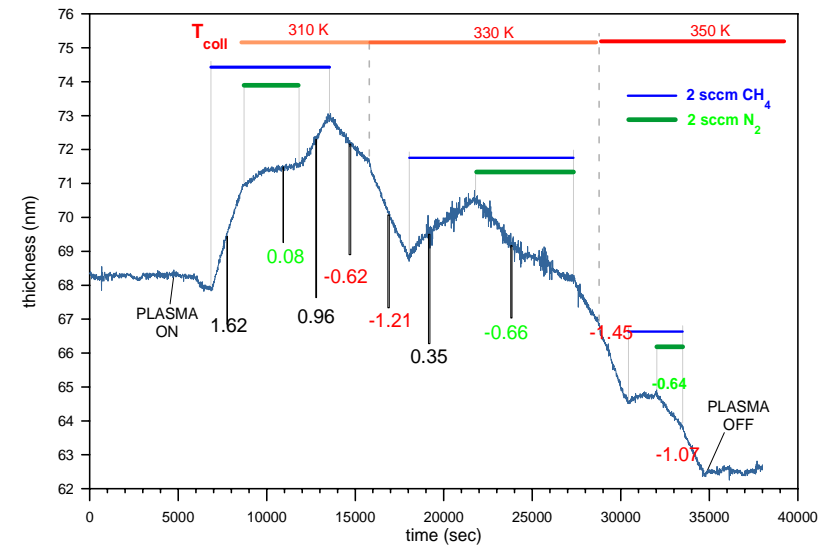

Fig.3:

Film thickness vs. time in the pump duct for three different collector temperatures while switching $\mathrm{N}_{2}$ and $\mathrm{CH}_{4}$ on and off. The numbers indicate the growth rate in $10^{-3} \mathrm{~nm} / \mathrm{s}$. Pressure $1 \mathrm{~Pa}$. 


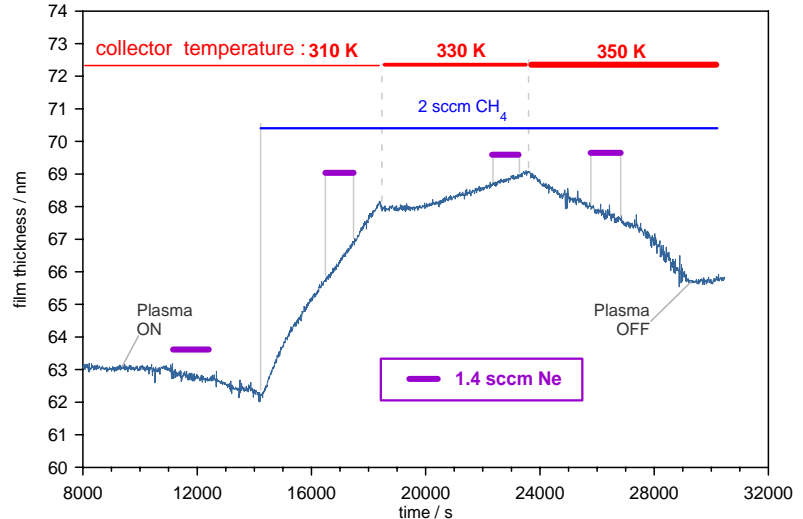

Fig. 4:

Film thickness vs. time for methane injection and additional neon injection at different collector temperatures. Pressure $1 \mathrm{~Pa}$. 


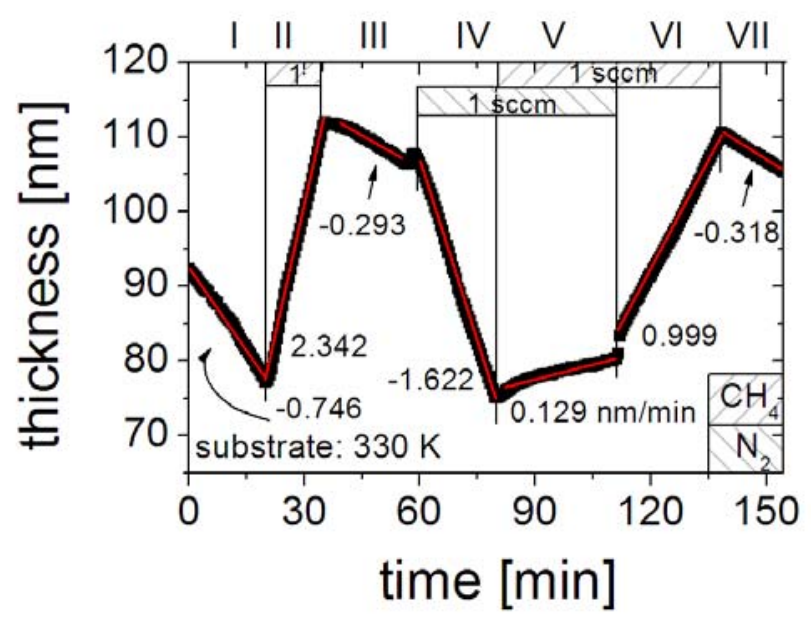

Fig.5: Change of film thickness in the main chamber vs. time for the injection of nitrogen and /or methane. The numbers indicate the growth rate in $\mathrm{nm} / \mathrm{min}$. For all phases the growth rates are given in numbers. 